\title{
Experimental improvement of honey bee (Apis mellifera) queen quality through nutritional and hormonal supplementation
}

\author{
Daiana A. De SouzA ${ }^{1}$, Ming Hua HuAng ${ }^{1,2}$, David R. TARPY ${ }^{1,3}$ \\ ${ }^{1}$ Department of Entomology and Plant Pathology, North Carolina State University, Raleigh, NC 27695-7613, USA \\ ${ }^{2}$ Eurofins Agroscience Services, Inc, Prospect Hill, NC, USA \\ ${ }^{3}$ W. M. Keck Center for Behavioral Biology, North Carolina State University, Campus Box 7613, Raleigh, NC 27695- \\ 7613, USA
}

Received 26 March 2018 - Revised 10 September 2018 - Accepted 15 October 2018

\begin{abstract}
Queen reproductive potential (=quality) impacts the health and productivity of honey bee colonies. To determine the factors that affect reproductive quality during development, we tested queens produced under larval treatments by supplementing the diet with juvenile hormone $(\mathrm{JH})$, additional sugars, or both, compared to untreated control. Furthermore, we varied the age of the larvae that were grafted ( 1 and 3 days old). We analyzed newly emerged virgin queens for their morphological characters as proxies for their reproductive potential. We found that the application of a sugar-enriched diet in combination with JH application onto 1st instar queen larvae produced higher-quality queens, while for 3rd instar larvae only the JH treatment resulted in increasing queen quality. For mated queens, those treated with JH plus supplemented sugars showed a significantly higher sperm count and sperm viability. Our findings demonstrate that honey bee queen reproductive potential can be increased through diet supplementation.
\end{abstract}

honeybee queens / queen quality / geometric morphometry / queen larval diet / juvenile hormone

\section{INTRODUCTION}

In honey bees (Apis mellifera L.), the reproductive capacity of a colony's queen is critical for worker production and colony growth, which results in higher colony fitness and successful swarms. However, there are major differences in how queens are produced and selected for the

Electronic supplementary material The online version of this article (https://doi.org/10.1007/s13592-018-0614-y) contains supplementary material, which is available to authorized users.

Corresponding author: D. Souza,

dalmeid@ncsu.edu

Daiana A. De Souza and Ming Hua Huang contributed equally to this work.

Manuscript editor: Klaus Hartfelder purpose of swarming and colony fitness, as well as how queens are produced in a managed context by beekeepers. During reproductive swarming of a wild or unmanaged colony, the colony's queen exhibits a reduction in her reproductive output through decreased oviposition. Her pheromones, which usually would inhibit the production of new queens (Pankiw et al. 2004), are less circulated among nestmates. Thereby, the colony is stimulated to produce new queen cells, enabling the old queen to leave the colony with a swarm just prior to the emergence of her daughter queens (reviewed by Winston 1987 and Seeley 2010). In contrast, beekeepers require large numbers of queens to restock their colonies, especially in countries that rely on packaged bees to raise new colonies, which are commonly produced by artificial queen rearing (see Laidlaw and Page 1997). During artificial queen rearing, eggs or, more 
frequently, young worker larvae are "grafted" into queen cells that are then introduced into a queenless hive environment, stimulating the queen-rearing behavior of nurse bees that feed the worker larvae royal jelly (Dedej et al. 1998; Tarpy et al. 2000). Because female larvae are totipotent until their third day of larval development, they are equally capable of developing into workers or queens. Those fed constantly with royal jelly are effectively raised as queens (Weaver 1957; He et al. 2017). Whether queens are reared naturally or artificially, they are nonetheless a critical component to colony fitness and productivity. Thus, maximizing their reproductive potential is of fundamental importance to both colonies and beekeepers (Amiri et al. 2017).

The quality of newly emerged queens is usually quantified by various external morphological features including thoracic width, wing length, and wet weight (Woyke 1971; Dedej et al. 1998; Hatch et al. 1999; Tarpy et al. 2000, 2011; Delaney et al. 2011; De Souza et al. 2013). Such morphological measures are convenient proxies for overall body size, which is highly associated with mating success (Delaney et al. 2011; Tarpy et al. 2011) and queen attractiveness to drones at mating flights (Nelson and Gary 1983; Gilley et al. 2003; Rangel et al. 2016). Queen size, and its associated phenotypes, is dictated almost entirely by the larval rearing environment, most notably the diet of royal jelly that the larvae receive throughout their development (Haydak 1970; Hartfelder et al. 2015) and temperature (deGrandi-Hoffman et al. 1993). The developmental trajectory toward high fertility is best quantified by measuring the capacity of the queen's ovaries and the spermatheca, the sperm storage organ. The size of these two organs is strongly associated with increased body weight at emergence, which has been used to score reproductive fitness among queens (Hoopingarner and Farrar 1959; Woyke 1967, 1971; Corbella and Gonçalves 1982; Dedej et al. 1998; Kahya et al. 2008; Tarpy et al. 2011).

The larval nutritional state, which is linked to the age of the larva selected for queen rearing, is directly related to the queens weight at emergence (Weaver 1957; Woyke 1971; Sagili et al. 2018). Older worker larvae shunted toward queen development emerge with fewer ovarioles and smaller spermathecae, resulting in a reduction in the number of sperm stored after their mating flights (Weaver 1957; Woyke 1971; Dedej et al. 1998; Tarpy et al. 2011). The importance of this variation in queen reproductive potential (=quality) is reflected in the productivity of their colonies. Some field studies have found that high-quality queens produced from newly hatched larvae and weighing more than $200 \mathrm{mg}$ at adult emergence headed significantly larger colonies than lowquality queens produced from old larvae and weighing less than $180 \mathrm{mg}$ at emergence. Queens weighing over $200 \mathrm{mg}$ headed colonies with higher brood populations, more stored pollen, and population growth (De Souza et al. 2013; Rangel et al. 2013).

The interaction between genetic background and rearing environment (the treatment provided by the nurses during the ontogenic development) is a crucial factor in the development of the female's fertility (Page and Fondrk 1995; Nijhout 2003; Kucharski et al. 2008; Leimar et al. 2012). The mechanisms underlying this interaction have attracted the attention of researchers for well over a century (reviewed by Hartfelder et al. 2015). The effects of differential feeding at the larval stage on fertility at adulthood and the intrinsic physiological and signaling pathways that drive this process have long been a focus of honey bee research. The role of juvenile hormone $(\mathrm{JH})$ as an inducer of ovarian development at the beginning of the larval phase is well established (Hartfelder and Engels 1998; Hartfelder and Emlen 2012). However, considerable progress on models of caste development has brought back into focus the role of sugar concentrations in larval food, which regulates the $\mathrm{JH}$ titers in the natural caste determination process (Leimar et al. 2012).

The commercialization and increased accessibility of synthetic JH (Staal 1971) enabled further advances in studies on the pleiotropic role of this hormone in insect metamorphosis and caste determination in general, particularly in honey bee queen development (Weaver 1974; Rembold et al. 1974a, b; Wirtz and Beetsma 1972). Specifically, the topical application of $\mathrm{JH}$ on worker larvae enabled the classic discovery of $\mathrm{JH}$ regulation of ovary development. High levels of $\mathrm{JH}$ in 
queen larvae during the last larval instar inhibit apoptosis in the ovary germ-cell clusters, preserving the development of ovarian filaments and resulting in highly fecund queens (Rachinsky and Hartfelder 1998; Rachinsky et al. 1990; Hartfelder and Steinbrück 1997; Schmidt Capella and Hartfelder 1998).

The role of $\mathrm{JH}$ during ovary development is not exclusive. Older inquiries have demonstrated the important role of sugars as phagostimulants, which results in increased $\mathrm{JH}$ synthesis in the corpora allata (Dogra et al. 1977; Rachinsky and Hartfelder 1998). The levels of different sugars (e.g., glucose and fructose) in the diet provided to honey bee female larvae change over the course of the first three larval instars when the larvae are totipotent (Asencot and Lensky 1985, 1988). While newly hatched worker larvae receive glandular secretions (worker jelly) with low levels of sugars that gradually rise through the larval instars, queen larvae receive a diet composed of higher sugar levels throughout the larval stage (Wang et al. 2016). Moreover, regulatory factors of physiological pathways in caste determination have been described through the integration of nutrient-sensing systems, in which the insulin-insulin-like signaling (IIS) and target-ofrapamycin (TOR) pathways play key roles in translating external nutritional signals to internal signals, biasing a larva's fate to the queen or worker adult phenotype (Patel et al. 2007; Mutti et al. 2011).

Despite these well-documented studies on caste development and their implications on reproductive potential, it is yet unknown if queen quality is already maximized in naturally reared queens (Sagili et al. 2018) or if there are any constraints during ontogenic development that can be artificially overridden to further improve reproductive quality. We hypothesized that the supplementation of the sugar levels in the diet provided to the larva at queen rearing and/or treatment of young larva with $\mathrm{JH}$ analogues could provide benefits to the reproductive quality of adult honey bee queens produced by grafting. Here, we demonstrate how these manipulations affect adult queen morphology and reproductive quality. Specifically, we show that queen quality can be increased in vivo by supplementing the royal jelly diet within queen cells with $\mathrm{JH}$ analog, additional sugars, or both. Our findings provide significant insights into reproductive development and fertility potential of honey bee queens.

\section{MATERIAL AND METHODS}

\subsection{Queen rearing and sample collection}

This study was conducted at the North Carolina State University Lake Wheeler Honey Bee Research Facility (Raleigh, North Carolina). We reared queens by grafting worker larvae of different age into queen cups to produce queens of either high or low reproductive quality by selecting younger and older larvae, respectively (Tarpy et al. 2011). We collected all queendestined larvae from the same parent colony of "Italian" bees, presumably derived from Apis mellifera ligustica. Thus, all experimental subjects were sisters to each other. For each of two rounds of queen rearing, the colonies' queens were caged for $8 \mathrm{~h}$ and the single age cohort of larvae was identified by marking their position at the brood comb on an acetate sheet. For the highquality queens (HQ), we grafted newly emerged larvae (1 day old) into queenless queen-rearing colonies and returned the brood frame to the parent colony. For the low-quality queens (LQ), we grafted a second set of larvae from the same brood source frame 2 days later (now 3 days old). Older larvae are not well accepted in queen-rearing colonies that already contain higher-quality queen larvae; thus, separate queen-rearing colonies were used for the LQ queens to ensure acceptance of the LQ queen larvae. This standard procedure resulted in two aged matched sets of queens, one of high reproductive quality (HQ) and the other of lower reproductive quality (LQ) (reviewed in Büchler et al. 2013).

We established four cell-builder colonies by removing their queen, ensuring adequate worker populations and supplementing their diet with $50 \%$ sucrose solution and pollen. Two cellbuilder colonies were designated for testing on HQ larvae and two colonies were designated for LQ larvae. When the queen larvae were in the 4th instar, approximately 3 and 1 days after grafting, we supplemented the naturally provisioned royal 
jelly with acetone only (control), JH only, additional sugars only, or both $\mathrm{JH}$ and additional sugars (Table I). Treatment positions were alternated within each queen-rearing colony to minimize any possible confounding effects of their localization in the colony. We applied juvenile hormone (SIGMA-ALDRICH \#J2000-50MG), diluted in acetone, by pipetting $1 \mu \mathrm{L}$ directly onto the surface cuticle of each larva at a dose of $2 \mu \mathrm{g}$ $\mathrm{JHIII} / \mu \mathrm{L}$ of stock solution. An acetone control group was included to account for any negative effects of the acetone solvent used to dilute the JHIII. For this acetone control group, $1 \mu \mathrm{L}$ of pure acetone was deposited onto the surface of the larva cuticle. An untreated control group without any acetone treatment was not required for the following reasons. First, acetone is highly volatile and evaporates from the surface of the larva relatively quickly, especially when such a small volume is applied $(1 \mu \mathrm{L})$. Second, the acetone never persisted in the queen cells because the acetone was applied on the larval cuticle and not into the diet. For the sugar supplementation treatments, we mixed a diet of $53 \%$ frozen royal jelly (GloryBeeß), $20 \%$ of glucose (SIGMA-ALDRICH \#G7021-1kg), 20\% of fructose (SIGMA-ALDRICH \#F0127-1kg), and $7 \%$ of $\mathrm{ddH}_{2} \mathrm{O}$. This recipe for supplementing sugars in queenrearing diet was based on the basic components of established artificial diets for rearing larvae in vitro (Rembold and Lackner 1981). For this study, we focused on maximizing the sugar and royal jelly components. All increases in sugar and royal jelly amounts were balanced with a decrease in water content. Using trial and error (data not

Table I. Experimental groups used in this study.

\begin{tabular}{ll}
\hline $\begin{array}{l}\text { High-quality grafting } \\
\text { larvae (1st Instar) }\end{array}$ & $\begin{array}{l}\text { Low-quality grafting } \\
\text { larvae (3rd instar) }\end{array}$ \\
\hline (1) Control 1 = acetone & (5) Control 2 = acetone \\
only & only \\
(2) Sugar & (6) Sugar \\
supplementation (T1) & supplementation (T1) \\
(3) JH (T2) & (7) JH (T2) \\
(4) JH plus sugar & (8) JH plus sugar \\
supplementation (T3) & supplementation (T3) \\
\hline
\end{tabular}

reported), we determined that the maximum amount of sugars that was dissolvable in the minimum amount of water was $20 \%$ glucose and $20 \%$ fructose. These sugar and water amounts then dictated the amount of royal jelly that we added. We then used a 3-mL syringe (FISHER \#14-8265D) with an 18-gauge needle (FISHER \#14-81752) to dispense $100 \mu \mathrm{L}$ of the viscous diet into the royal jelly already present within each queen cell. Each acetone control larva that did not receive any additional sugar was given the same amount of supplemented food diet consisting of royal jelly and water but without the additional sugars. After food supplementation, we waited 5 min after application to allow any potentially noxious volatiles to vaporize. We then returned the larvae to their respective rearing colonies. We removed the capped queen cells from each colony and allowed the queens to emerge into individual glass vials held inside of an incubator set at $34{ }^{\circ} \mathrm{C}$ (Laidlaw and Page 1997). We checked the incubated capped cells for queen emergence once a day, and we noted the adult emergence success for each experimental group (Table II).

\subsection{Newly emerged virgin queen assessments}

Virgin queens from each experimental group were frozen immediately after emergence and evaluated for their potential fecundity. First, we recorded the wet body weight $( \pm 0.1 \mathrm{mg})$ of each virgin queen using a digital scale. Second, we measured their thorax width and head width $( \pm 0.1 \mathrm{~mm})$ using digital calipers. Third, we removed one of the two hind legs from each queen and mounted it on a glass slide to determine their respective basitarsus index (length-width ratio measured at $\times 40$ ) using an ocular micrometer. Fourth, we removed one of the two forewings from each queen and mounted it on a glass slide to measure wing length using an ocular micrometer (measured at $\times 40$ ).

\subsection{Open-mated queen assessments}

We produced a second subset of high-quality queens that were all derived from larvae grafted at 1 day old. These larvae were treated with either JH 
Table II. Grafting replicates and emergence success of different experimental groups: high-quality (HQ) grafting larvae (1-day old), reared at QR2 and QR4 colonies and low-quality (Q) grafting larvae (3-day old), reared at QR1 and QR3 colonies.

\begin{tabular}{llllll}
\hline $\begin{array}{l}\text { Experimental } \\
\text { groups }\end{array}$ & $\begin{array}{l}\text { Rearing } \\
\text { colony }\end{array}$ & $\begin{array}{l}\text { Experimental } \\
\text { group }\end{array}$ & $\begin{array}{l}\text { Number grafted } \\
\text { and treated } \\
\text { larvae }\end{array}$ & $\begin{array}{l}\text { Number } \\
\text { emerged* }\end{array}$ & $\begin{array}{l}\text { \% successful } \\
\text { emergence }\end{array}$ \\
\hline Acetone only & QR2 & HQ & 13 & 11 & 84.6 \\
& QR4 & HQ & 23 & 19 & 82.6 \\
& QR1 & LQ & 48 & 22 & 45.8 \\
& QR3 & LQ & 48 & 18 & 37.5 \\
Sugar & QR2 & HQ & 22 & 13 & 59.1 \\
augmentation & QR4 & HQ & 34 & 23 & 67.7 \\
& QR1 & LQ & 80 & 9 & 11.3 \\
& QR3 & LQ & 80 & 2 & 2.5 \\
JH & QR2 & HQ & 23 & 23 & 100 \\
& QR4 & HQ & 34 & 27 & 79.4 \\
& QR1 & LQ & 48 & 21 & 43.8 \\
& QR3 & LQ & 48 & 16 & 33.3 \\
JH plus sugar & QR2 & HQ & 23 & 18 & 78.3 \\
augmentation & QR4 & HQ & 35 & 19 & 54.3 \\
& QR1 & LQ & 80 & 10 & 12.5 \\
& QR3 & LQ & 80 & 7 & 8.8 \\
\hline
\end{tabular}

*All newly emerged queens with extremely deformed wings were considered as "not fit" and were not counted in the "Number Emerged."

plus additional sugars (treatment T3) or acetone (control) to assess queen mating success. We decided to choose the T3 group over the T1 (sugar supplementation only) and $\mathrm{T} 2$ ( $\mathrm{JH}$ only) group because the T3 group had the highest potential to produce high-quality queens based on the morphometric data on virgin queens, thus testing the extremes as a priority over intermediate groups. We established 10 mating nucleus colonies from unrelated hive sources for rearing queen cells for each of the two experimental groups. We recorded each virgin queen's body weight immediately after emergence before introducing her to her respective mating nucleus. After each queen successfully mated and initiated oviposition, we sacrificed her to measure her ovary weight, spermatheca diameter, total sperm count, number of sperm, and sperm viability. We quantified all sperm measurements by dissecting the spermatheca from each queen and placing it into $1000 \mathrm{~mL}$ of saline buffer $(0.9 \% \mathrm{NaCl})$ and rupturing it with forceps to mix. The solution was pipetted into an amber chromatography vial containing $10 \mathrm{~mL}$ of Syber 14 (Invitrogen Live/Dead sperm staining kit \#L7011; 1mM in DMSO) diluted 1:500 into dimethylsulfoxide $(99.8 \%)$ and $10 \mathrm{~mL}$ propidium iodide solution ( $2.4 \mathrm{mM}$ in water). We vortexed each vial for $2 \mathrm{~s}$ at $2000 \mathrm{rpm}$ to homogenize the mix but avoid shearing of sperm (which increases mortality). We allowed the homogenized mix to sit a minimum of $5 \mathrm{~min}$ to ensure an adequate uptake of the dyes into the cells. We quantified the samples using a Nexcelom Cellometer® Vision Cell Counter with settings for the fluorescence at $1200 \mathrm{~ms}$ for the Syber 14 (which binds to the acrosome of live sperm cells) and $7000 \mathrm{~ms}$ for the propidium iodide (which binds to the acrosome of dead sperm cells). We counted each sample three times in different locations to mitigate clumping, taking the average sperm count and viability for each queen. After dissection, we also measured the queen's head width, thorax width, 
wing length, and basitarsus index as outlined above.

\subsection{Statistical analysis}

A factorial ANOVA was used to compare the pre-copulatory morphometric measures among the different treatments such as wet weight at emergence, developmental time, wing length, basitarsus index, head width, and thorax width. The morphological features were also analyzed using principal component analysis (PCA). Because all morphological and reproductive measures were positively correlated, this enabled us to reduce the total set of partly inter-correlated variables to two uncorrelated principal components (PC1 and PC2). This analysis was performed using the average values of weight at emergence, developmental time, wing length, basitarsus index, head width, and thorax width from samples of each treatment groups (De Souza et al. 2015). Then, factorial ANOVA was performed based on the factor coordinates calculated by the PCA to determine the impact of the treatments on the morphology as a whole. For the open-mating test, one-way ANOVA, followed by Bonferroni post hoc tests, was used to compare the pre-copulatory measures (weight at emergence, head width, thorax width, basitarsus index, and days to emergence) and post-copulatory measures (age to start laying eggs, colony establishment time, ovary weight, spermatheca diameter, total sperm count, and sperm viability). The analyses were performed with the software STATISTICA 7.0.

\section{RESULTS}

\subsection{Newly emerged virgin queen assessments}

The successful emergence at adult stage was statistically affected by the age at which the larvae were grafted $\left(F_{(1,7)}=212.1, p<0.00001\right)$ across all treatments (Table II), with the highest success among high-quality queens compared to lowquality queens. The JH application did not affect the emergence rates of the high- and low-quality queens $\left(F_{(1,3)}=0.10, p=0.76\right)$ Table S3.
The findings demonstrate that the larval age when grafted had a significant impact on all morphological features classically associated with queen quality (Figure 1 and Table S1). Newly emerged queens raised from younger larvae exhibited shorter developmental time, higher weight at emergence, and greater head, thorax, basitarsus, and wing size than queens raised from older larvae (Figure 1 and Table S1). The supplemented sugaronly treatment (T1) significantly increased the development time (especially among the lowquality queens) and reduced the size of the wings when compared to the control group. For the JH III-only treatment (T2), head and thorax widths were significantly increased in both the high- and low-quality groups (Figure 1 and Table S1). The combination of sugar supplementation with the JH III treatment (T3) affected almost all analyzed morphological features, including a decreased average development time and increased weight, head width, thorax width, and wing length. The only morphological feature not affected by the T3 treatment was basitarsus index (Figure 1 and Table S1).

The PCA showed that the two main components accounted for approximately $72 \%$ of the variance among the newly emerged queens raised from larvae of different ages (HQ and LQ queens) and treated with different supplementations (sugar only = T1; JH III only = T2; sugar + JH III = T3) (Figure $2 \mathrm{~b}$ and Table S2). The correlations of the treatments applied with the two first components are given as vectors in the biplot (Figure 2a). It is important to note that PC1, which accounted for $54.9 \%$ of the variance, was negatively correlated with almost all features evaluated except for the time of development (age at emergence). The PC2 axis, which accounted for $16.7 \%$ of the variance, is positively correlated with developmental time, and head and thorax width (Figure 2a). By analyzing PC1, we observe a significant difference between queens raised from larvae of different ages (Figure 2c). The HQ queens cluster on the left of the graph and LQ queens cluster on the right, confirming that this factor effectively discriminates the morphological characteristics analyzed. The sugar supplementation treatments (T1 and T3) were also significantly different for PC1 (Figure $2 \mathrm{~d}$ ), and this divergence was confirmed by 
a

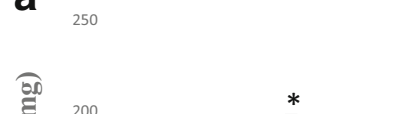

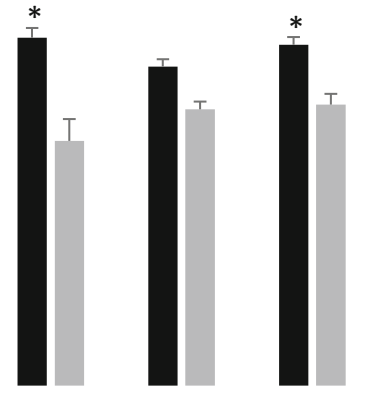

C

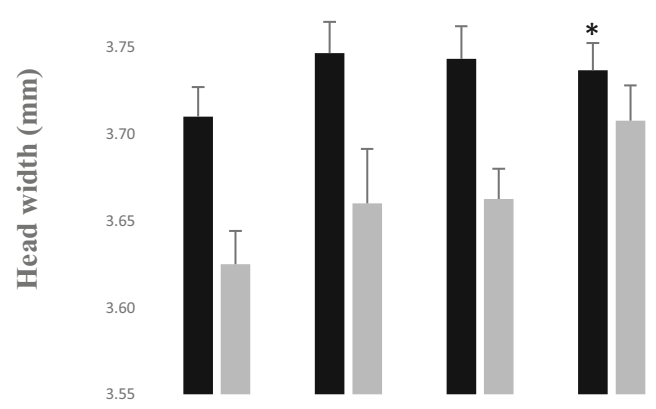

e

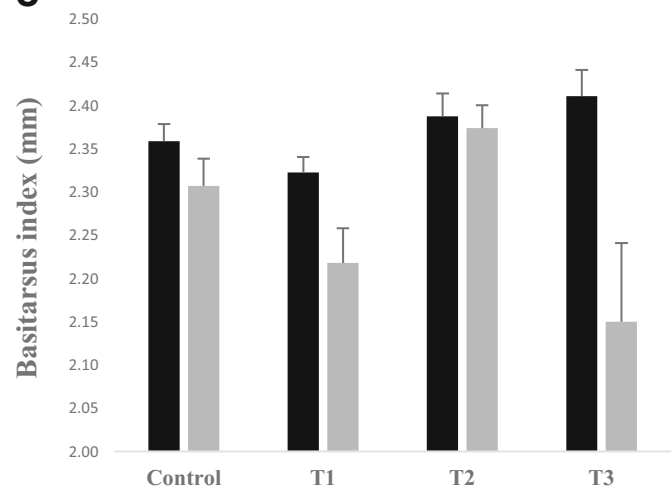

b

- HQ $\quad$ LQ

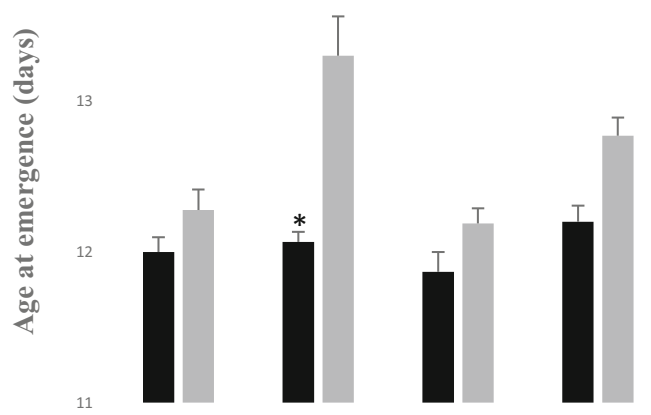

d

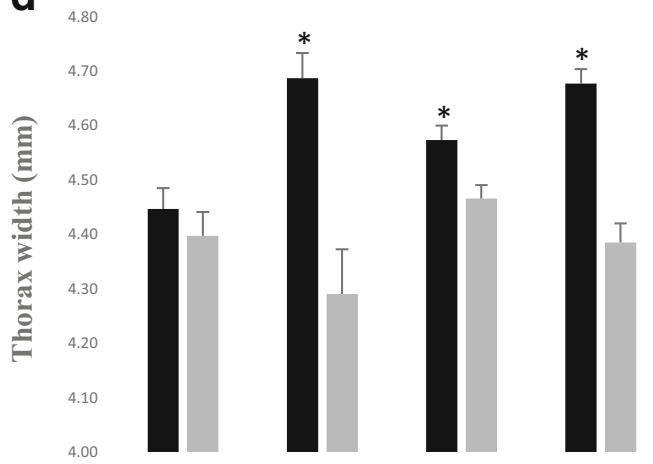

f

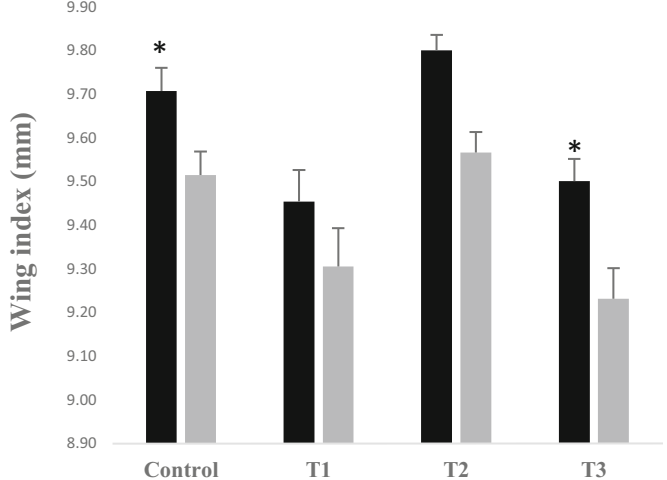

Figure 1 Mean $( \pm \mathrm{SD})$ morphological features of newly emerged queens raised with high- and low-quality grafting larvae (1-day old and 3-day old) and different treatments: sugar supplementation, T1; JH III, T2; sugar supplementation + JH III, T3. a Weight at emergence. b Developmental time. c Head width. d Thorax width. e Basitarsus index. f Wing length. *Significance $p<0.05$.

the factorial ANOVA where T1 and T3 were statistically different from the control $\left(F_{(1,27)}=7.91\right.$, $p=0.009$ and $F_{(1,27)}=11.78, p=0.001$, respectively). In contrast, only $\mathrm{T} 2$ significantly diverged morphologically from the control among LQ queens $\left(\mathrm{T} 1, F_{(1,9)}=2.38, p=0.15\right.$; T2, $F_{(1,34)}=$ 5.53, $p=0.02$; T3, $F_{(1,15)}=0.46, p=0.50$; Figure 2e). 
a

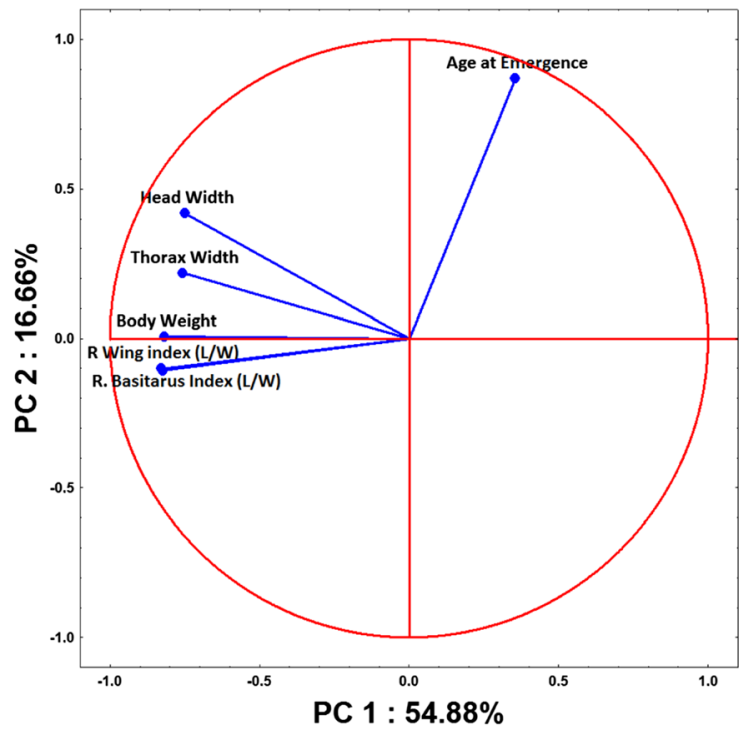

b

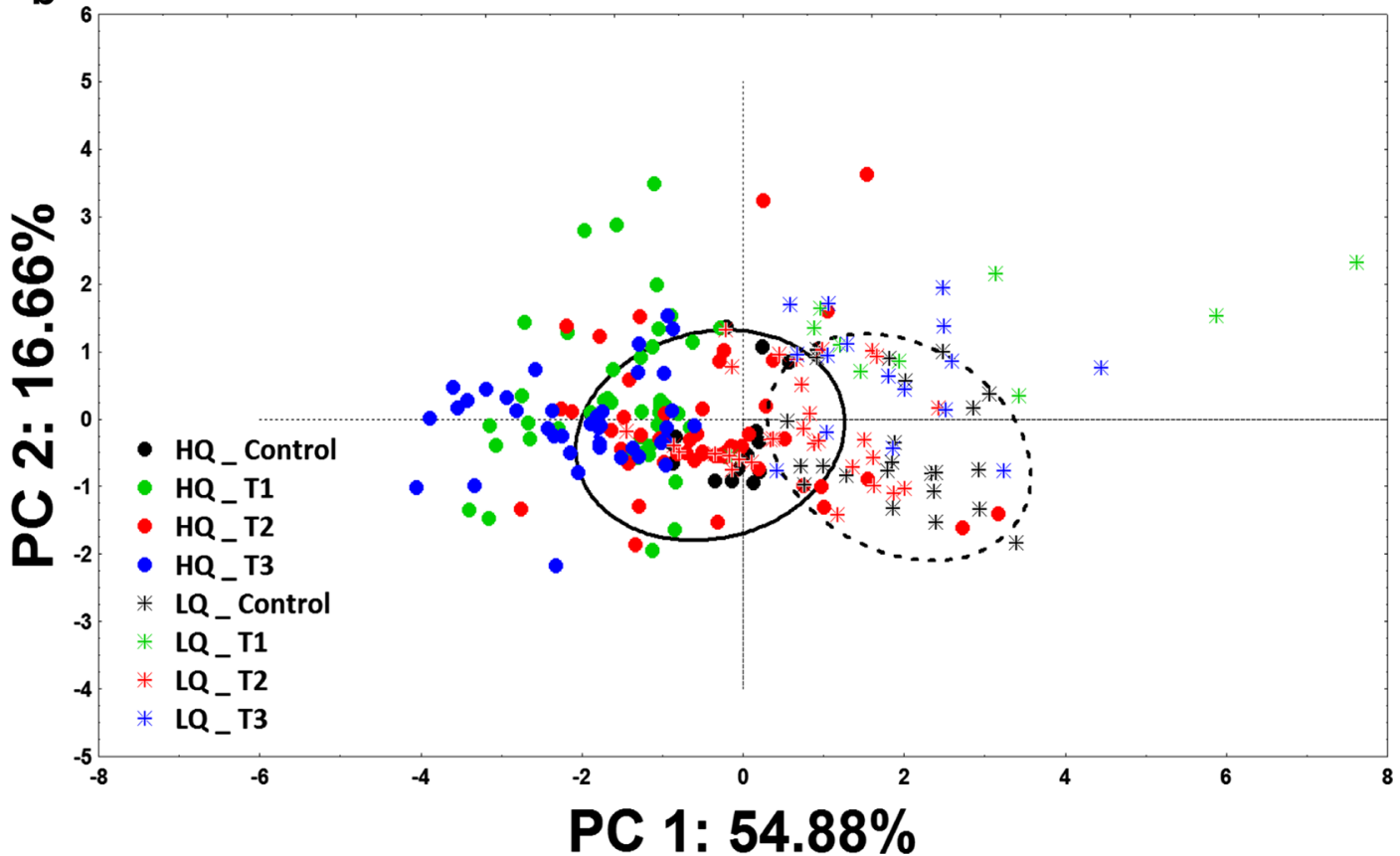

Figure 2 Results from PCA based on the average values of queens' morphometric features (weight at emergence, developmental time, head width, thorax width, basitarsus index, and wing length). a Projection of the characteristics of the first two components, showing the correlations between the features values with PC1 and PC2. b Distribution of newly emerged queens, reared from different larvae age HQ and LQ (1- and 3-day old larvae) and treatment (sugar supplementation, T1; JH III, T2; sugar supplementation + JH III, T3), through the first two principal components. The ellipse represents the grouping of the control high-quality queens (bold line) and low-quality queens (hatched line), based on morphological similarity. c Projection of distribution of newly emerged queens, grouped only by different larval age (HQ and LQ). d Projection of distribution of HQ newly emerged queens under with different treatments (sugar supplementation, T1; JH III, T2; food supplementation + JH III, T3). e Projection of distribution of LQ newly emerged queens treated with different treatment (sugar supplementation, T1; JH III, T2; sugar supplementation + JH III, T3). 

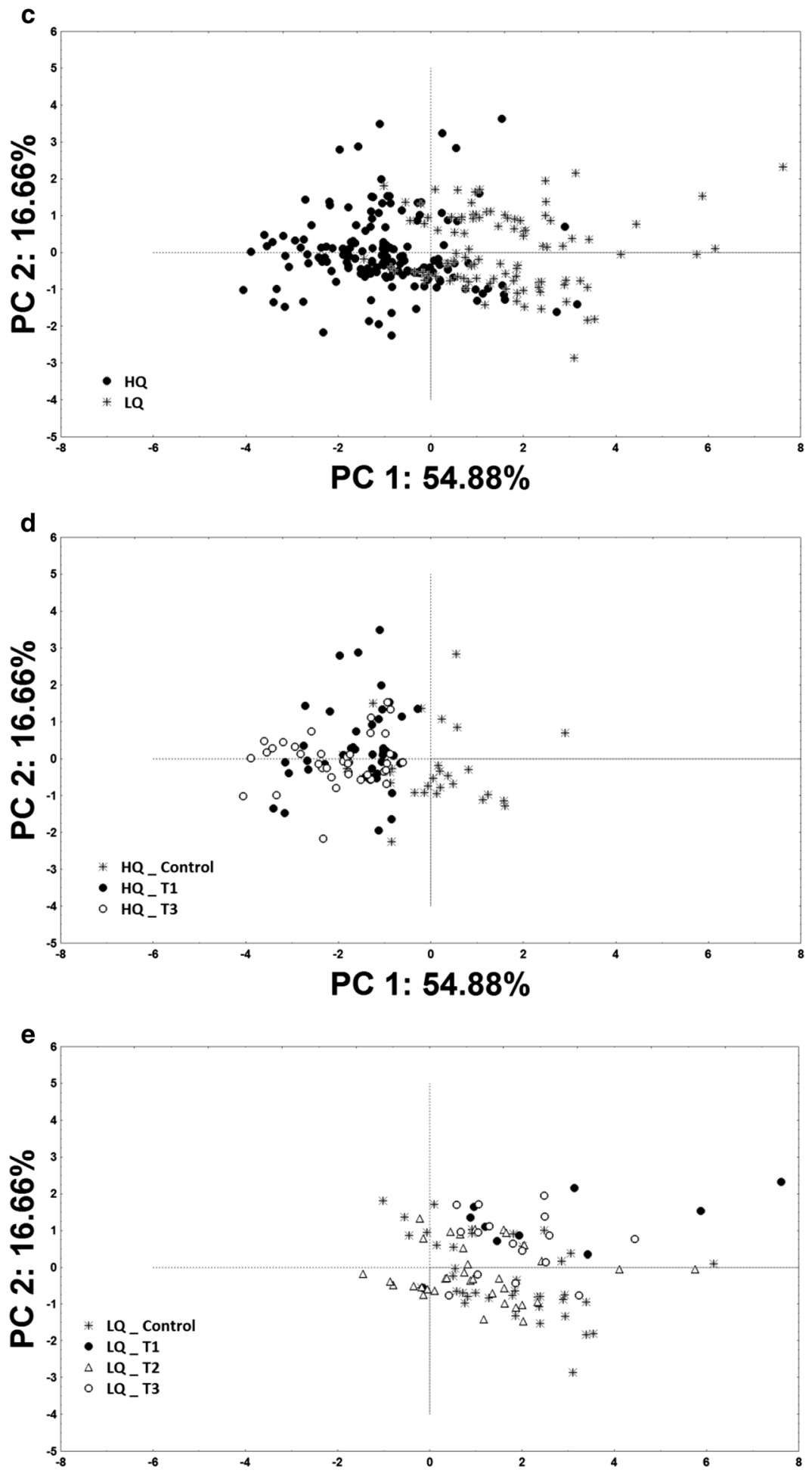

Fig. 2 (continued).

PC 1: $54.88 \%$ 


\subsection{Open-mated queen assessments}

For the open-mated queens, two experimental groups were used: HQ larvae treated with acetone (control) and HQ larvae treated with JH plus sugar supplementation (T3) (see Table S3). Regrettably, only three of the ten emerged virgin queens in the acetone control group, and four of ten emerged virgin queens in the T3 group (JH plus sugar supplementation) ultimately mated and successfully established colonies. There was no noticeable difference between the two groups in the number of days until emergence $\left(F_{(1,5)}=1.05, p=0.35\right)$. The same as was observed in latency to egg-laying $\left(F_{(1,5)}=0.76, p=0.42\right)$ and colony establishment $\left(F_{(1,6)}=0.18, p=0.68\right)$ (Table S3a). Precopulatory morphometric measurements of body weight, head width, thorax width, wing length, and basitarsus index for T3 (JH plus sugar supplementation) were consistent with the values for high-quality queens found in the earlier replications (Table S3b). Two of the four post-mating traits that were examined (Table S3c), despite being numerically greater in the T3 queens, were not statistically significantly affected by the treatment: ovary weight $\left(F_{(1,5)}=2.53, p=0.17\right.$; Figure 3a) and spermatheca diameter $\left(F_{(1,5)}=3.64, p=0.11\right.$; Figure $3 b)$. However, the sperm count $\left(F_{(1,5)}=\right.$ $12.90, p=0.015$; Figure $3 \mathrm{c})$ and the number of viable $\operatorname{sperm}\left(F_{(1,4)}=19.58, p=0.011\right.$; Figure $\left.3 \mathrm{~d}\right)$ were significantly greater in T3-treated queens than the control queens. Despite this, the percentage of viable sperm was not significantly different between control (avg. $=87.7 \pm 20.0 \%)$ and $\mathrm{T} 3$ mated queens $($ avg. $=88.0 \pm 13.1 \%)\left(F_{(1,4)}=\right.$ $0.01, p=0.93$; Table S3c). Note that there was one sample from the treatment group that was excluded from the analysis because it was an

\section{a}

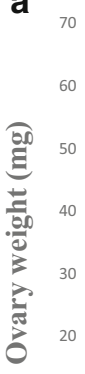

00

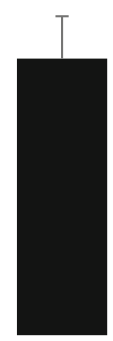

C

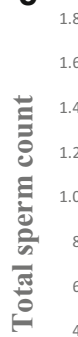

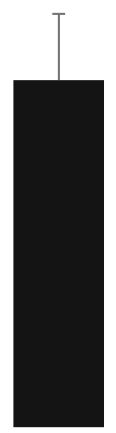

b

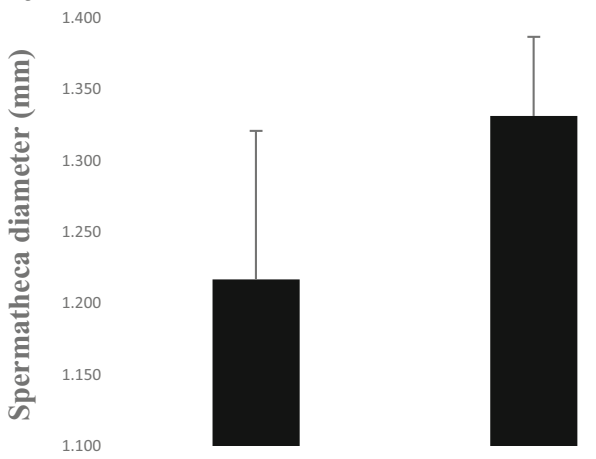

d

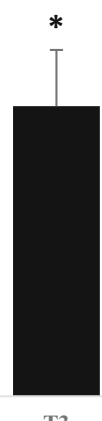

T3

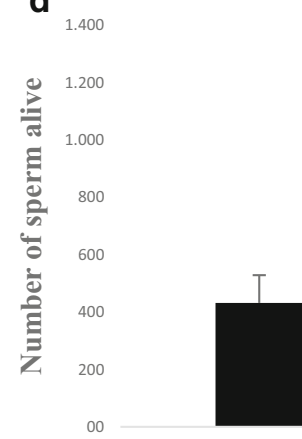

Control

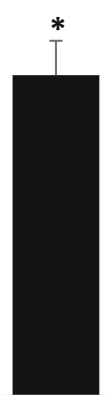

T3

Figure 3. Post-copulation means $( \pm \mathrm{SD})$ of a ovary weight, $\mathbf{b}$ spermatheca diameter, $\mathbf{c}$ total sperm count, and $\mathbf{d}$ sperm viability of queens reared using young larvae under sugar supplementation treatment + JH III, T3. *Significance $p<0.05$. 
extreme outlier (total sperm count $=1.329,800$; sperm viability $=7.5 \%$, number of live sperm $=$ 99,735).

\section{DISCUSSION}

The search to improve honey bee queen reproductive quality is one of the main goals of apicultural research. Here, we took advantage of the high developmental plasticity in the queen ontogenic development (Tarpy et al. 2011; Rangel et al. 2013; De Souza et al. 2013) attributed to the already well-known physiological pathways involved on this process (Barchuk et al. 2007; Hartfelder et al. 2015) to investigate whether manipulating the amount of sugars and/or $\mathrm{JH}$ in food during honey bee queen larval development would increase queen reproductive potential. First, we wanted to test if these manipulations can further improve the quality of queens reared from optimal (young) female larvae that exceed the reproductive capacity of queens reared by usual grafting methods. Our findings confirmed that raising virgin queens from younger-grafted larvae produced significantly higher-quality queens than grafting from older larvae. We also showed that the application of a sugar-enriched royal jelly in combination with $\mathrm{JH}$ application into queen cells of young grafted larvae produce higher-quality virgin queens than using younger larvae without this food supplementation. JH supplementation is known to be effective in inducing queen-like morphological characters when topically applied to honey bee worker larvae, even at lower doses than those used here (Dietz et al. 1979; Rembold et al. 1974a, b). Thus, initially we expected JH application to be a more significant driving force in improving queen quality, especially concerning the weight at emergence, since the high level of this hormone in queen larva is responsible for ovary development, which is closely associated to the weight at emergence (Schmidt Capella and Hartfelder 1998, 2002; Reginato and Cruz-Landim 2001). Interestingly, the application of juvenile hormone alone to young larvae did not improve the reproductive quality of virgin queens, at least with regard to their external morphological features used to estimate reproductive quality.

Second, we wanted to test if these same manipulations can help "rescue" the reduced quality of queens reared from sub-optimal (older) larvae, and we found that the $\mathrm{JH}$ treatment applied on older larvae induced some significant reproductive improvements among virgin queen quality, unlike other treatments (Figure 2). However, this improvement did not reach the level of the high-quality queens. For older larvae, the sugar supplementationonly treatment consistently resulted in lower queen quality traits. One possible explanation for this effect is that older larvae begin to slow down their food consumption in the natural colony environment, where larval care is continuously monitored by adult nurse bees. The concentration of fructose and glucose during the first three instars is significantly lower in the larval diet of workers but rise suddenly during 4th feeding day to levels even higher than those found in queens (Wang et al. 2016). Therefore, the combination of older larvae and the sudden increase of sugar levels could have had an inverse effect, thereby simulating worker bee development instead of queen development. This possibility is supported by the findings related to time of development until adulthood, in which the LQ-T1 queens took significantly more time to emerge as adults.

The LQ groups exhibited a very low acceptance rate among all treatment groups. This is not a surprising result since the difficulties in acceptance of older grafted larvae for rearing of queens are well described (Tarpy et al. 2016). During emergency queen rearing, nurse bees occasionally prefer construction of queen cells around older worker larvae since they are closer in development to adult emergence. However, more than half of these cells are torn down before emergence (Hatch et al. 1999; Tarpy et al. 2011; Long et al. 2017). Among the HQ groups, acceptance was higher in the JH-only treatment group than in the sugar supplementation treatment group, suggesting that sugar supplementation affects acceptance of treated larvae by the nurse bees within the colony, 
although our experiment was not designed to test this directly.

During open mating, the queens treated with JH plus supplemented sugars (T3) showed a significantly greater number of viable sperm and total sperm count than queens reared without any larval treatment (Figure 3), consistent with previous findings about high-quality queens (Tarpy et al. 2011). Interestingly, the T3 queens (high-quality queens) and the control queens shared a similar average percentage of viable sperm (Table S3c). A likely reason for this result is that the T3 queens may have an ability to maintain more viable sperm, driven by their ability to accumulate a greater total sperm count. Previous studies demonstrated that higher-quality queens tend to be larger in body size, and presumably able to mate with more males and physically store more sperm (Woyke 1967, 1971; Corbella and Gonçalves 1982; Delaney et al. 2011; Tarpy et al. 2011). It is also possible that the higher-quality queens are better able to mitigate the mortality of stored sperm compared to lower-quality queens (Tarpy et al. 2011).

The common practice for commercial queen rearing is to visually select the smallest (youngest) larvae for grafting. Although this practice already yields high-quality queens (Tarpy et al. 2012; Rangel et al. 2013), we show here that it is possible to achieve even higherquality queens by providing a sugar-rich royal jelly supplement into the queen cells along with $\mathrm{JH}$ application. The addition of this protocol can be implemented at a relatively low monetary and time cost. While we were not able to "rescue" diminished queen quality by adding JH to 3rd instar larvae, hormone supplementation of 1 st instar larvae has the potential to improve reproductive quality as well. Further research is needed to better understand the impact of these treatments on queens, colony performance, and commercial apiculture. The direct implications of our findings has the potential for further improvement of queen quality will not only benefit commercial queen breeders but it may also help the commercial pollination industry that rely on queen breeders to supply replacement queens.

\section{ACKNOWLEDGEMENTS}

We are thankful to Jennifer Keller, Sam Freeze, and Michael Simone-Finstrom for their help in the field and sample collection.

\section{FUNDING INFORMATION}

This work was partially supported by a grant from the National Honey Board.

Amélioration expérimentale de la qualité de reine des abeilles (Apis mellifera) grâce à une supplémentation nutritionnelle et hormonale

Reines des abeilles / qualité de la reine / morphométrie géométrique / régime alimentaire des larves de reine / hormone juvénile

Experimentelle Verbesserung der Qualität von Honigbienen-Königinnen (Apis mellifera) durch Ernährungs- und Hormon-Ergänzungsstoffe

Honigbienen-Königinnen / Königinqualität / Geomoetrische Morphometrie / Larvendiät der Königin / Juvenilhormon

\section{REFERENCES}

Amiri E, Strand MK, Rueppell O, Tarpy DT (2017) Reduced queen quality and honey bee diseases: Interactions between two major threats to colony health. Insects 8: 48

Asencot M, Lensky Y (1985) The phagostimulatory effect of sugars on the induction of "queenliness" in female honeybee (Apis mellifera L.) larvae. Comp. Biochem. Physiol. Part A: Physiol. 81 (1), 203-208

Asencot, M., Lensky, Y. (1988) The effect of soluble sugars in stored royal jelly on the differentiation of female honeybee (Apis mellifera L.) larvae to queens. Insect Biochem. 18 (2), 127-133

Barchuk AR, Cristino AS, Kucharski R, Costa LF, Simoes ZLP, Maleszka R (2007) Molecular determinants of caste differentiation in the highly eusocial honeybee Apis mellifera. BMC Devel. Biol.7: 70

Büchler R, Andonov S, Bienefeld K, Costa C, Hatjina F, Kezic N, Kryger P, Spivak M, Uzunov A, Wilde J (2013) Standard methods for rearing and selection of Apis mellifera queens, J. Apic. Res. 52:1, 1-30, https://doi.org/10.3896/IBRA.1.52.1.07

Corbella E, Gonçalves LS (1982). Relationship between weight at emergence, number of ovarioles, and 
spermathecal volume of africanized honeybees queens Apis mellifera L. Rev. Bras. Gen. 5, 835-840

De Souza DA, Bezzera-Laure MAF, Francoy TM, Gonçalves, LS (2013) Experimental evaluation of the reproductive quality of Africanized queen bees (Apis mellifera ) on the basis of body weight at emergence. Gen. Mol. Res. 12 (4): 5382-5391. https://doi. org/10.4238/2013.November.7.13

De Souza DA, Wang Y, Kaftanoglu, O, De Jong D, Amdam GV, Gonçalves LS, Francoy TM (2015) Morphometric Identification of Queens, Workers and Intermediates in In Vitro Reared Honey Bees (Apis mellifera). PLoS ONE 10(4): e0123663. https://doi.org/10.1371/journal.pone. 0123663

Dedej S, Hartfelder K, Aumeier P, Rosenkranz P, Engels W (1998) Caste determination is a sequential process: Effect of larval age at grafting on ovariole number, hind leg size and cephalic volatiles in the honey bee (Apis mellifera carnica). J. Apic. Res. 37: 183-190

DeGrandi-Hoffman GM, Spivak M, Martin JH (1993) Role of thermoregulation by nestmates on the development time of honey bee (Hymenoptera: Apidae) queens. Ann. Entomol. Soc. Am. 86, 165-172

Delaney DA, Keller JJ, Caren JR, Tarpy DR (2011) The physical, insemination, and reproductive quality of honey bee queens (Apis mellifera). Apidologie 42, 1-13.

Dietz A, Hermann HR, Blum MS (1979) Role of exogenous JH-I, JH-III and Anti-JH (Precocene-II) on queen induction of 4.5-day-old worker honey bee larvae. J. Insect Physiol. 25, 503e512

Dogra GS, Ulrich GM, Rembold H (1977) A comparative study of the endocrine system of the honey bee larvae under normal and experimental conditions. $\mathrm{Z}$. Naturforsch. 32, 637-642

Gilley DC, Tarpy DR, Land BB (2003) The effect of queen quality on the interactions of workers and dueling queen honey bees (Apis mellifera L.). Behav. Ecol. Sociobiol. 55: 190-196

Hartfelder K, Emlen DE (2012) Endocrine control of insect polyphenism. In: Gilbert L.I. (Ed.) Insect Endocrinology. London: Academic Press, pp. 464-522

Hartfelder K, Engels W (1998) Social insect polymorphism: Hormonal regulation of plasticity in development and reproduction in the honeybee. Curr. Top. Dev. Biol 40, 45-77

Hartfelder K, Steinbrück G (1997) Germ cell cluster formation and cell death are alternatives in caste-specific differentiation of the larval honey bee ovary. Invertebr. Repr. Dev. 31 (13), 237-250

Hartfelder K, Guidugli-Lazzarini KR, Cervoni MS, Santos DE, Humann FC (2015) Old threads make new tapestry - Rewiring of signalling pathways underlies caste phenotypic plasticity in the honey bee, Apis mellifera L. Adv. Insect Physiol. 48, 1e36

Hatch S, Tarpy DR, Fletcher DJC (1999) Worker regulation of emergency queen rearing in honey bee colonies and the resultant variation in queen quality. Insect. Soc. 46: $372-377$
Haydak M (1970) Honey bee nutrition. Annu Rev Entomol. 15: 143-156

He XJ, Zhou LB, Pan QZ, Barron AB, Yan WY, Zeng ZJ (2017) Making a queen: An epigenetic analysis of the robustness of the honeybee (Apis mellifera) queen developmental pathway. Mol Ecol. 26(6):1598-1607

Hoopingarner R, Farrar CL (1959) Genetic control of size in queen honeybees. J. Econ. Entomol. 52, 547-548

Kahya Y, Gençer HV, Woyke J (2008) Weight at emergence of honey bee (Apis mellifera caucasica) queens and its effect on live weights at the pre and post mating period. J. Apic. Res. 47(2), 118-125

Kucharski, R., Maleszka, J., Foret, S. \& Maleszka, R. 2008. Nutritional control of reproductive status in honeybees via DNA methylation. Science, 319:1827-1830

Laidlaw Jr HH, Page Jr RE (1997) Queen Rearing and Bee Breeding. Cheshire: Wicwas.

Leimar O, Hartfelder K, Laubichler MD, Page Jr RE (2012) Development and evolution of caste dimorphism in honeybees - a modeling approach. Ecol. Evol. 2, 3098-3109

Long K, Cao TT, Keller JJ, Tarpy DR, Shin M, Schneider SS (2017) Levels of selection shaping caste interactions during queen replacement in the honey bee, Apis mellifera. Insect. Soc. 64:227-240 https://doi. org/10.1007/s00040-016-0537-4

Mutti NS, Dolezal AG, Wolschin F, Mutti JS, Gill KS, Amdam GV (2011) IRS and TOR nutrient-signaling pathways act via juvenile hormone to influence honey bee caste fate. J Exp Biol., 214: 3977-3984

Nelson DL, Gary NE (1983) Honey productivity of honey bee Apis mellifera colonies in relation to body weight attractiveness and fecundity of the queen. J. Apicult. Res. 22: 209-213

Nijhout HF (2003) Development and evolution of adaptive polyphenisms. Evol. Dev. 5:9-18.

Page RE, Fondrk MK (1995) The effects of colony-level selection on the social organization of honey bee (Apis mellifera L.) colonies: Colony-level components of pollen hoarding. Behav. Ecol. Sociobiol. 36:135-144

Pankiw T, Roman R, Sagili RR, Zhu-Salzman K. 2004. Pheromone-modulated behavioral suites influence colony growth in the honey bee (Apis mellifera). Naturwissenschaften, 91: 575-578

Patel A, Fondrk MK, Kaftanoglu O, Emore C, Hunt G, Frederick K, Amdam GV (2007) The making of a queen: TOR pathway is a key player in Diphenic caste development. PLoS ONE 2:509

Rachinsky A and Hartfelder K H (1998) Corpora allata activity, a prime regulating element for caste-specific juvenile hormone titre in honey bee larvae (Apis mellifera carnica). J Insect Physiol 36, 189-194 https://oi.org/10.1016/0022-1910(90)90121-U

Rachinsky A, Strambi C, Strambi A, Hartfelder K (1990) Caste and metamorphosis - Hemolymph titers of juvenile hormone and ecdysteroids in last instar honeybee larvae. Gen. Comp. Endocrinol. 79, 31-38 
Rangel J, Keller JJ, Tarpy DR (2013) The effects of honey bee (Apis mellifera L.) queen reproductive potential on colony growth. Insect. Soc. 60, 65-73

Rangel J, Böröczky K, Schal C, Tarpy DR (2016) Honey bee (Apis mellifera) queen reproductive potential affects queen mandibular gland pheromone composition and worker retinue response. PLoS ONE, 11: e0156027

Reginato RD, Cruz-Landim C (2001) Differentiation of the worker's ovary in Apis mellifera L. (Hymenoptera, Apidae) during the life of the larvae. Invert. Reprod. Develop. 39: 127-134

Rembold, H., \& Lackner, B. (1981). Rearing of honey bee larvae in vitro: Effect of yeast extract on queen differentiation. Journal of Apicultural Research, 20, 165-171.

Rembold H, Czoppelt C, Rao PJ (1974a) Effect of juvenile hormone on caste differentiation in the honey bee. Apis mellifera. J. Insect Physiol. 20, 1193-1202

Rembold H, Lackner B, Geistbeck J (1974b) The chemical basis of queen bee determinator from royal jelly. J. Insect Physiol. 20, 307-314

Sagili RR, Metz BN, Lucas HM, Chakrabarti P, Breece CR (2018) Honey bees consider larval nutritional status rather than genetic relatedness when selecting larvae for emergency queen rearing. Sci Rep. 8(1):7679. https://doi.org/10.1038/s41598-018-25976-7

Schmidt Capella IC, Hartfelder K (1998) Juvenile hormone effect on DNA synthesis and apoptosis in castespecific differentiation of the larval honey bee (Apis mellifera L.) ovary. J. Insec. Physiol. 44, 385-391

Schmidt Capella IC, Hartfelder K (2002) Juvenilehormone-dependent interaction of actin and spectrin is crucial for polymorphic differentiation of the larval honey bee ovary. Cell Tissue Res. 307, 265-272

Seeley TD (2010) Honeybee Democracy. Princeton University Press, Princeton

Staal GB (1971) Practical aspects of insect control by juvenile hormone. Bull. Wid Hith Org.44(1-2-3):391-394

Tarpy DR, Hatch S, Fletcher DJC (2000) The influence of queen age and quality during queen replacement in honeybee colonies, Anim. Behav. 59, 97-101
Tarpy DR, Keller JJ, Caren JR, Delaney DA (2011) Experimentally induced variation in the physical reproductive potential and mating success in honey bee queens. Insect. Soc. 58, 569-574

Tarpy DR, Keller JJ, Caren JR, Delaney DA (2012) Assessing the mating 'health' of commercial honey bee queens. Journal of Economic Entomology, 105: $20-25$

Tarpy DR, Simone-Finstrom M, Linksvayer TA (2016) Honey bee colonies regulate queen reproductive traits by controlling which queens survive to adulthood. Insect. Soc. 63: 169. https://doi.org/10.1007/s00040015-0452-0

Wang Y, Ma L, Zhang W, Cui X, Wang H, Xu B (2016) Comparison of the nutrient composition of royal jelly and worker jelly of honey bees (Apis mellifera). Apidologie 47:48-56

Weaver N (1957) Effects of larval age on dimorphic differentiation of the female honey bee. Ann. Entomol. Soc. Am. 50, 283-294

Weaver N (1970) Control of dimorphism in the female honeybee. 2. Methods of rearing larvae in the laboratory and of preserving royal jelly. J. Apic. Res.13: 3-14

Weaver N (1974) Control of dimorphism in the female honeybee. 3. The balance of nutrients. J. Apic. Res. 13, 93-101

Winston ML (1987) The biology of the honey bee. Harvard University Press, Cambridge, Mass. 281p.

Wirtz P, Beetsma J (1972) Induction of caste differentiation in the honey bee (A. mellifera) by juvenile hormone. Entomol. Exp. Appl. 15, 517-520

Woyke J (1967) Rearing conditions and the number of sperm reaching the queen's 395 spermatheca. XXI Int. Beekeep. Congress Summer, 93pp.

Woyke, J (1971) Correlations between the age at which honeybee brood was grafted, characteristics of the resultant queens and results of insemination. J. Apic. Res. 10(1): 45-55 